\title{
Threshold Variations in Cortical Cell Assemblies and Behavior
}

\author{
N. Birbaumer, W. Lutzenberger, T. Elbert, \\ AND T. TREVORROW
}

There is nothing new under the sun, which is especially true for the neurosciences ${ }^{1}$. Our present situation is best described by the Italian poet Eugenio Montale:

Codesto solo oggi possiamo dirti, ciò che non siamo, ciò che non vogliamo.

Was heut' wir ságen können, ist nur das, was wir nicht sind, was wir nicht wollen.

Today we can only say

what we are not, what we don't want.

\footnotetext{
${ }^{1}$ Our theoretical position on electrocortical mechanisms (described in detail in Birbaumer et al., 1990) is based on Hebb's $(1949,1961)$ concept of cell assemblies. The neuroanatomy of cell assemblies is described by V. Braitenberg and his group (Braitenberg, 1978, 1984; Braitenberg and Schüz, 1991; Schüz and Palm, 1989), and the mathematical modeling rests on algorithms and ideas applied by Palm (1982) and Elbert (1987; Elbert and Rockstroh, 1987). Mayer-Kress et al. (1988), Freeman (1991), and Basar, Basar-Eroglu, and Schult (1989) were forerunners in the use of deterministic chaos for the analysis of fast EEG changes to describe the status of cell assemblies.
} 
Before we concentrate on the behaviot-modifying properties of cortical potentials, let me clarify our position about the meaning of brain electrical activities in more general terms, because it deviates from the now-prevailing view of cognitive neuroscience or what we call neuropsychoanalysis: eventrelated potential components interpreted as psychoanalysts interpret dreams. By using this term we want to indicate that cognitive psychophysiologists tend to interpret brain electrical activities by inventing catchy names such as in the case of the N400: "semantic mismatch wave" (Kutas and Hillyard, 1980 ), and by doing so the inferred information processing stage seems to become real; at least there seems to be a corresponding brain processes. In reality, in the case of the $\mathrm{N} 400$, for example, incongruent words or sentences, like any other type of incongruity or inconsistency, can elicit a rather unspecific cortical mobilization. We described such phenomena in the early 1970 s, and maintain that little is gained if we give them catchy names. It has been obvious for well over a decade that large negativities can be generated in many parts of the brain if priming or mobilization of cell assemblies is called for or activated by external stimulation (Elbert et al., 1982; Rockstroh et al., 1979). Figure 1 represents the result of an early experiment in which the experimental situation becomes ambiguous, or when "control" over

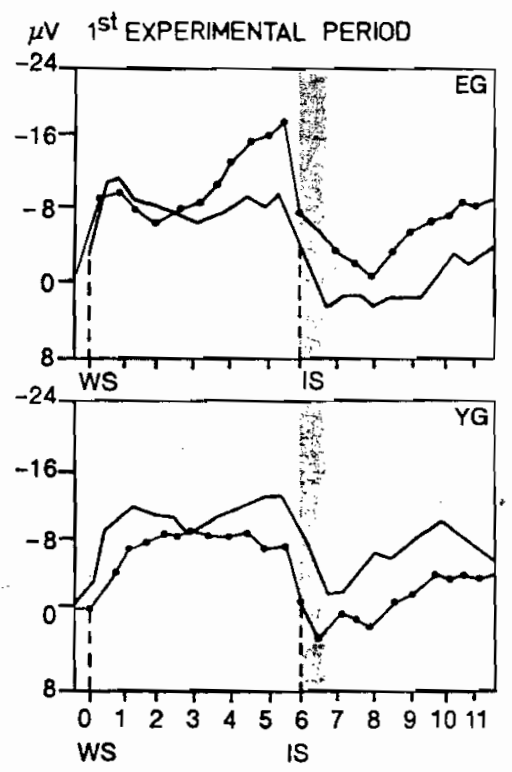

$2^{\text {nd }}$ EXPERMENTAL PERIOD

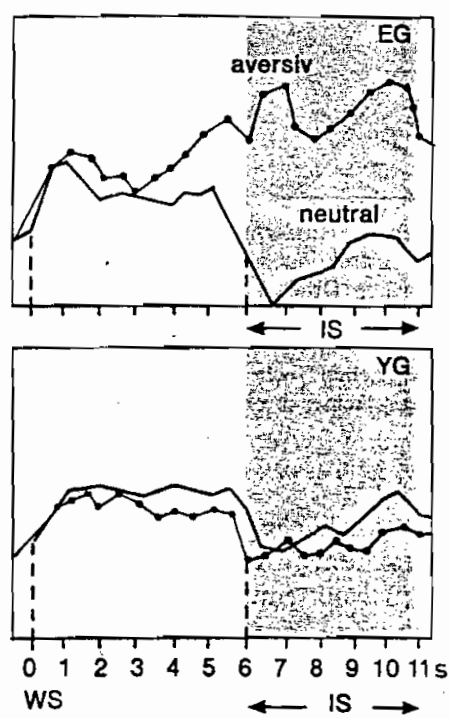

Figure 1. Large negative postimperative variation (PINV) after loss of control in experimental group (EG, right column) for aversive stimulation only. Neutral imperative stimuli (IS, hatched line) do not lead to PINV if the behavioral control (left column, first experimental period) is lost (right column). Control group had no control over IS duration throughout experiment. (from Rockstroh et al., 1979.) 
experimental stimuli is withdrawn from the subject. If the subject's expectancy is violated, a poststimulus negative wave develops. Situations with semantic incongruities are but a special case of general priming in arousing conditions.

Cognitive psychophysiologists are tireless inventors of event-related EEG components. Perhaps they hope that their so-called "information processing stages" may ultimately be accepted by the brain, which eventually succumbs under those cognitions and does what it is supposed to do. Before relating the components and waves of event-related potentials to some poorly defined psychological concepts, one should consider the physiological basis of those waves in cortical tissue. If physiological reality matches with psychological terminology, the latter may also receive a breeze of physical reality.

\section{Surface Potentials Indicate Neural Excitability}

There is solid neurophysiological evidence, particularly from the work of Caspers, Speckman, and Elger, that local negative variations of the upper cortical layer reflect a lowering of excitation thresholds for the respective assembly. This is not clear for positive variations, which may result from dipole inversion accompanying deeper layer firing or a reduction of upper layer firing. Analysis by Mitzdorf (1985) indicated that most positivities we see in the EEG reflect an increase of excitatory thresholds.

Macroscopically measured potentials largely result from excitatory post-synoptic potentials (EPSPs) in the dendritic trees of the cortex. Stellate cells do not produce open extracellular far-fields. What we see on the scalp or the surface of the cortex is primarily the summation of postsynaptic potentials at pyramidal cells (see also Mitzdorf, 1985). Consequently, a surfacenegative potential signifies depolarization of the dendritic tree in vast networks of pyramidal cells, hence indicating an increment in excitability of the underlying cortical tissue.

This suggests that the apical dendritic tree is a candidate for the regulation of cortical excitability thresholds. Depolarization of the apical dendrites causes an efflux of negative charges into extracellular space and back into the neuron in the deeper layers. This results in a polarization of the cortex with the negative pole near the surface. A lowering of thresholds for cortical excitability will result in an increase in surface negativity, while a positive wave is generated when thresholds are set high; therefore, a positive wave, such as the P3, corresponds to an interruption of ongoing activity and to a dysfacilitation of widespread neural activity.

There is also experimental evidence from macroscopic recordings supporting these statements. For instance, drugs that decrease cortical excitability proportionately decrease slow surface negativity. While various anti- 
convulsant drugs may exhibit quite different effects on earlier components of visual and auditory evoked potentials, as well as on spontaneous EEG activity (Rockstroh et al., 1987, 1991), they all lower CNV (contingent negative variation) amplitude and also the negative DC (direct current) shifts obtained during hyperventilation (Rockstroh, 1990; von Bülow et al., 1989). Certain stimulant drugs may enhance the $\mathrm{CNV}$, although several results have been paradoxical (for review, see McCallum, 1988).

\section{The Concept of Cell Assemblies and Aspects of Memory Storage}

The concept of cell assemblies (Hebb, 1949) has become fundamental to models concerned with the functioning of the brain, even though many neuroscientists were reluctant for some 10 or 20 years to accept the lesson they had to learn from a psychologist. Hebb $(1949,1961)$ postulated that short-term memory is represented in reverberatory circuits, as described earlier by Lorente de No (1943). Once activated, these circuits can maintain excitation as they are formed by a set of neurons, each of which receives excitation from, and gives excitation to, other members of the same set. If a sufficiently large number of neurons in one such cell assembly is activated, the whole set will become active.

The "trick" to memory storage is that the structure of these cell assemblies is flexible and can be changed rapidly. This requires the strengthening of connections between simultaneously active neurons (Hebb's rule), an assumption that has long been considered the physiological basis of learning and memory storage (Hebb, 1949). It is thought that within neural networks the ability of simultaneously active synapses to depolarize the postsynaptic membrane is increased above a certain level of postsynaptic activity, while insufficient activation weakens active synapses. [This is based on Hebb's rule; models of the memory have been suggested by Palm (1982) and others.]

It is generally assumed that plasticity is realized through N-methyl-Daspartat (NMDA) receptors (for evidence and models of synaptic plasticity, see Bear, Cooper, and Ebner, 1987; Gustafson et al., 1987). Probably all the synapses on spines are subject to modification in their strength, which would mean that three of four cortical synapses are plastic (Braitenberg and Schüz, 1991). Therefore, the buildup and strengthening of a cell assembly requires that a large portion of cells not relevant for the concept of the incoming event be shut off; otherwise, connections would form randomly. Consequently, cortical excitability must be reduced for a fraction of a second or so before a relevant event can be stored in long-term memory.

On the basis of the considerations of the previous section, we have concluded that the widespread reduction in cortical excitability, or inhibition, respectively, will manifest in a widespread positive wave an the scalp (Birbaumer and Elbert, 1988). There is evidence that the P300, and in part 
the positive slow wave, reflect exactly this process. $\mathrm{P} 300$ has been linked to the updating of memory (Donchin and Coles, 1988), and is thought to reflect processes associated with the maintenance of a model of the environment. The larger the information transmission, the more cells should be involved in the network. As updating information must be isolated from background activity, the dysfacilitation must be more widespread, and positivity should increase in expansion and hence in amplitude.

An interesting example of the experimental evidence confirming the inhibitory/disfacilitatory character of the P3 was provided by Rockstroh et al. (1991). Probe clicks to which subjects were asked to respond were delivered during the time course of (an auditory-oddball) P3. Reaction times were significantly slowed, and probe-elicited ERPs were reduced at times when a P3 was present. A comparable RT slowing was not observed in subjects who responded with a pronounced slow negative wave to the targets. These findings are consistent with the proposed dysfacilitatory process.

\section{Brief Outline of the Threshold Regulation Model}

To summarize the consequence of such a Hebbian view for the interpretation of EEG and ERPs:

1. The development of cell assemblies depends on plastic ("Hebbian") excitatory cell systems with a rapid rise time for their construction. The system ideally suited for this purpose are the apical pyramidal dendritic trees of the upper neocortical layer.

2. A cell assembly includes sometimes widespread cortical neurons including sensory, cognitive (meaning), and motor functions. Any restrictive separation into highly specialized "modules," as is fashionable in present-day neuropsychology, is obsolete, vis-a-vis the fact that every sufficiently large pool of neurones of the cortex is connected to every other neuronal pool, forming the anatomic basis of our illusion of a unified consciousness. The meaning and qualitative nature of an event, an idea, an emotion, or a percept, is reflected in the local topography, the topographical "gestalt" of an assembly not in the properties of its parts, the cells or its transmitters.

3. This specificity of an assembly is best reflected in the spatial distribution and frequency of fast-changing electrical activities, such as the EEG and ERP components. It has to be fast because assemblies must have the ability to ignite explosively as a whole: a whisper can turn on a full-blown paranoid delusion within the fraction of a second, including all, or nearly all, sensory, motor, and meaning aspects of that delusion.

4. Cell assemblies, and therefore the EEG and ERP, should have properties of deterministic chaos: They cannot be totally random, as it would be impossible to create new ideas and percepts if assemblies did not generate novel activity patterns within the fraction of a thought. Rapid-state changes 
and bifurcations are characteristics of cell assemblies, which are sensitive to very weak initial conditions that lead instantly to widespread changes in the whole system. These two elements also characterize chaotic systems. Freeman (Freeman, 1991; Skarda and Freeman, 1987) has shown, in the olfactory system of the rabbit, that chaos becomes more prevalent when there is competition between parts of assemblies or between several assemblies. We believe that we have hints for a similar mechanism for cognitive processes in the human neocortex (see following).

5. Whether a given assembly will be ignited and the "contrasts" between assemblies (their foreground-background Gestalt) depends on the threshold of an assembly. Usually assemblies are excited by external or internal stimuli; more frequently, they are primed by conditioned stimuli occurring before a stimulus that ultimately ignites the assembly. In addition to externally controlled threshold regulation, cell assemblies have their own automatic threshold control, so as to, as Braitenberg poetically states, "discover and isolate ideas ..." and to reinforce ideas "and keep them separately" (Braitenberg and Schüz, 1991, p. 205) (Fig. 2). Another main function of automatic threshold control is to prevent the transition from an "Einfall to an Anfall" (transition from an idea to a seizure) in an excitatory neuronal network. Inherent to threshold control is its nonlinear transformation of information. Therefore, we should apply principles from nonlinear systems theory (deterministic chaos) to understand the dynamic patterns of threshold regulation. As illustrated in the following section, slow cortical potentials (SCP) seem to be a rather useful tool to measure stimulus-response or "idea"organization. Local negativity represent lowering of thresholds; local positivities represent augmented thresholds for assembly ignition. Because of the inhibitory nature of threshold control, and the lack of much inhibition in the neocortical architecture, subcortical routes are taken that need more time than for the excitatory ignition of assemblies.

We present here some recent data from our laboratory illustrating the points we have made on the chaotic properties of fast EEG and ERP components.

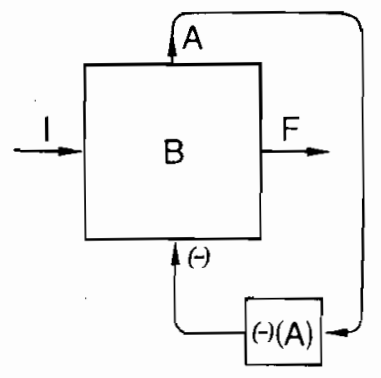

Figure 2. Threshold control. Brain $B$ with input $I$ and functional output $F$ has in addition output $A$ that signals total activity; this is fed into a mechanism of threshold control that sets thresholds of all components at certain level $\Theta$. Form of dependence $\Theta(A)$ may vary. [From Braitenberg V, \& Schüz A (1991): Anatomy of the Cortex. Statistics and Geometry, Berlin: SpringerVerlag.] 


\section{Deterministic Chaos in Neural Cell Assemblies}

Why introducing deterministic chaos in connectionistic models of brain function and cognition?. We (Birbaumer et al., 1990; Lutzenberger et al., 1992), and others before us (Basar, et al., 1989; Freeman and Skarda, 1987) have pointed out that without the presence of chaotic electrical processes the formation of new, unlearned percepts (such as odors) and sensory-motorpatterns cannot be conceptualized or simulated. The chaotic activity has to be deterministic and nonrandom because living biological systems can only function if held within certain activity limits through feedback of the ongoing activity. On the other hand, nonlinear changes in the state of neural cell assemblies (NCAs) is a prerequisite of any living system to generate new sensory-motor patterns that control the environment in a dynamic, everchanging way, patterns that depend on slightly different initial conditions and consequences.

As Freeman (Skarda and Freeman, 1987) has put it, chaos provides the NCAs with a "deterministic 'I don't know' ": Without it, the patterned activity would always return to old, already-formed NCAs leading to exhausting repetition. However, any group of NCAs can be pressed into linear deterministic activity for a certain time period by highly structured external or internal variations. Some pathological conditions, and repetitive behavior without competitive activity, may fall into this category.

Classical behavioral psychology and neuroscience have for a long time exclusively studied linear processes such as habituation or sensitization to simple stimulus configurations. With regard to cognitive activity in the brain ("thinking"), we hypothesize that with increasing competition between NCAs of different cortical localization, the phase space in which a corresponding EEG activity varies becomes multidimensional. On a psychological level, this may correspond to an increasing "dissipation" of the attentional focus. In new situations with multimodal memory demands, the dimensionality ("complexity") of the EEG should be higher. This is similar to the Basar et al. (1989) description of increased coherence of the EEG phase space with increased probability of stimulus occurrence in simple cognitive tasks, and decreased coherence with increasing difficulty to predict stimulus occurrence.

\section{Intelligence and Brain Chaos}

If our hypothesis is correct, the dimensionality of the human EEG should increase with higher processing capacities, as measured by tests of intelligence. Dimensionality in one context is described as the ability of a certain space to contain a set of points from a time series, such as the EEG. Mathematically, we are calculating the fractal dimensions of the EEG trace and the fractal dimension of the EEG attractor. An attractor is the "frozen" dynamics of a system, if left without external perturbations. (For methodological details, see Lutzenberger et al., 1992). In theory, the more dimensions 
low $1 Q$
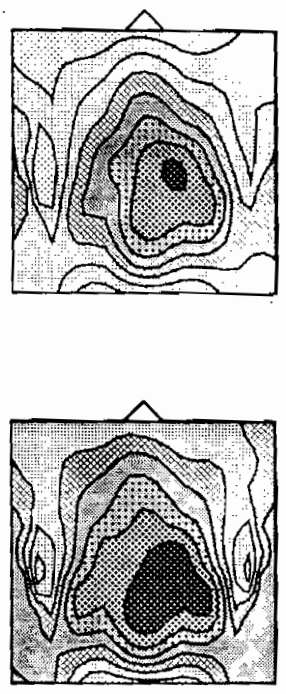

EEG dimension

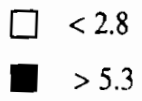

high IQ

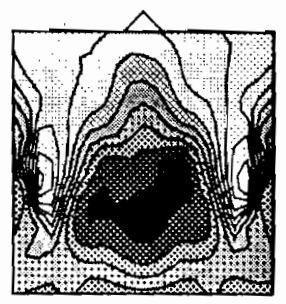

res!

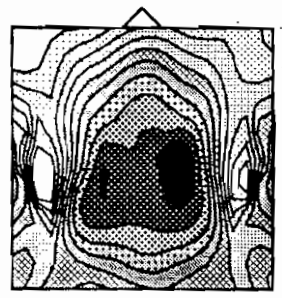

image

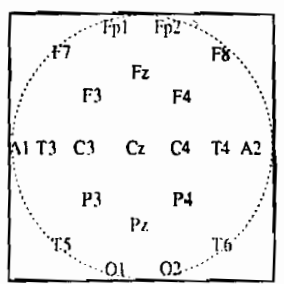

Figure 3. Chaotic dimensions of 20 EEG channels (lower right) of 10 Ss with high IQs $(<110)$ and $10 \mathrm{Ss}$ with low IQs $(>90)$. Darker color indicates increased dimensions. (From: Lutzenberger W, Birbaumer N, Flor H, Rockstroh B, Elbert T, (1992) Dimensional analysis of the human EEG and inteligence. Neuroscience Letters 143, 10-14. Reprinted with permission.)

of the space state, the more we need to localize all points of our time series within this space, and the more independent processes are building our empirically found time series.

Intelligence may be defined in accordance with Rohracher's subtle description (Rohracher, 1976) of the "performance level of psychological functions for the solving or coping with new situations" "Der Leistungsgrad psychischer Funktionen bei der Bewältigung neuer Situationen").

Twenty male subjects, (Ss), selected to differ on a broad range in IQ levels (CFT, culture-free intelligence test of Cattell) performed a concentration test (continuous performance test, CPT), engaged in emotional imagery, 
and participated in eyes-open rest, during which 16 EEG channels were recorded according to the 10-20 system. The chaotic dimensions of the EEG (frequency range, $2-35 \mathrm{~Hz}$ ) channels were calculated by using singular value decomposition (factor analysis) and the reference point method (Mayer-Kress et al., 1988). Data were collected of groups of 20 resting EEGs (2048 values) and in groups of $20 \mathrm{EEG}$, during imagining "the most pleasurable" and "the most aversive scene" of the Ss life. EEG $\alpha$ - and $\beta$-power were transformed for demonstration purposes constructing "brain chaos maps" (Fig. 3). Figure 3 demonstrates the pronounced and significant $[F(1,18)=7.3$, $p<.01$ ] difference between 10 Ss with IQs above average and 10 Ss with IQs below 100 (median split). Higher IQs exhibited approximately five-dimensional phase space during rest; lower IQs exbibited only three to fourdimensional phase space, particularly at central-parietal locations.

Tests of concentration (d2, Bourdon test) and personality questionnaires measuring risk for psychopathology failed to show meaningful differences in EEG dimensionality. Positive and negative emotional content of the image had no influence on the EEG complexity. However, Figure 4 indicates that the EEG dimensionality does not represent a task-independent trait variable such as IQ. During imagery, the differences between high and low IQ groups vanishes: the low-IQ Ss EEGs becomes significantly more complex, whereas the high-IQ Ss EEGs become simpler. Figure 4 also indicates that data from an independent sample of medical students (whose average IQ is usually above 100) confirms the positive relationship between IQ and increasing dimensionality.

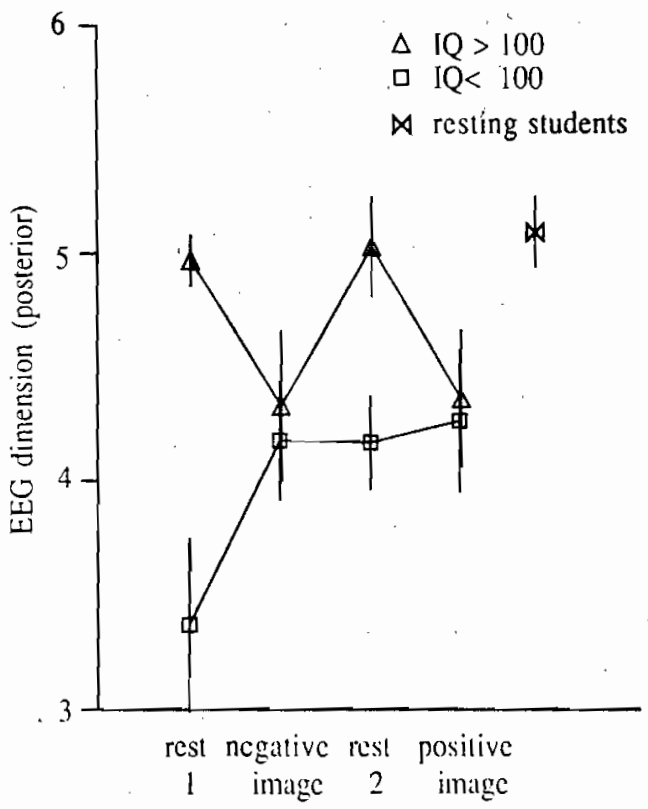

Figure 4. Chaotic dimensions of parietal EEG during rest condition and during emotionally negative and positive image (see text for explanation). 
In an earlier study (Lutzenberger et al., 1992), we used a variety of tasks that cut across sensory modalities including touch, vision, imagery, and verbal processing that reflect neuropsychological processes which differentially engage both the frontal and more posterior areas of the cortex. The outcome shows variations between scalp sites for all measures and also variations between tasks in terms of dimensionality of the EEG attractor as well as of dimensionality of the EEG trace itself. A statistical comparison between the maps generated by means of the various measures shows that different informations are extracted when using the different measures. Results demonstrate that traditional Fourier analyses only extract limited information from the EEG and thus do not present a complete picture.

The methodology of nonlinear dynamics seem to result in higher brain variability for nonprimed situations, with an interaction between different memories of sensory and motor modalities. If task demands are primed by preceding signals, the electric activity turns into a more deterministic mode, represented more clearly, as mentioned earlier, by slow brain potentials. Rest, fantasizing, imagery, nonorientated "free-floating" thinking, etc. do not directly determine threshold regulation as does immediate goal-oriented behavior, reflected in SCPs positivities and negativities. For those more spontaneous processes, rhythmicity is mandatory and higher dimensions are expected. Let us return to those situations in which highly deterministic goal-directed behavior and thought are produced by low excitatory thresholds of local NCAs, in particular those of the apical dendrites of the neocortex.

\section{Changes in Slow Cortical Potentials Facilitate or Retain Behavior and Thought}

During the past 15 years we have tried to illustrate the threshold-regulating properties of SCPs with different methodologies. As an example that departs from classical psychophysiological experimentation, we summarize studies utilizing operant conditioning of slow cortical potentials.

In a series of studies (reviewed in Birbaumer et al., 1990; Rockstroh et al., 1989) using healthy Ss and clinical patients, Ss learned to control local negativities and positivities of 6- to 10-sec duration using the biofeedback device that we developed in the late 1970s (Elbert et al., 1980) and the principal operation of which is illustrated in Figure 5.

Ss watched a TV screen that displayed their slow cortical potentials (SCP) from a particular scalp location. SCPs are presented continuously, and are represented by an outlined rocket ship moving back and forth in a horizontal plane for 6-10 seconds per trial (depending on experimental questions). The closer the rocket moves towards two vertical bars on the right, the more negative or positive the particular potential has become. Appearance of the letter A or B on each trial indicates whether positivity or negativity should be produced. Correct responses are usually reinforced with 


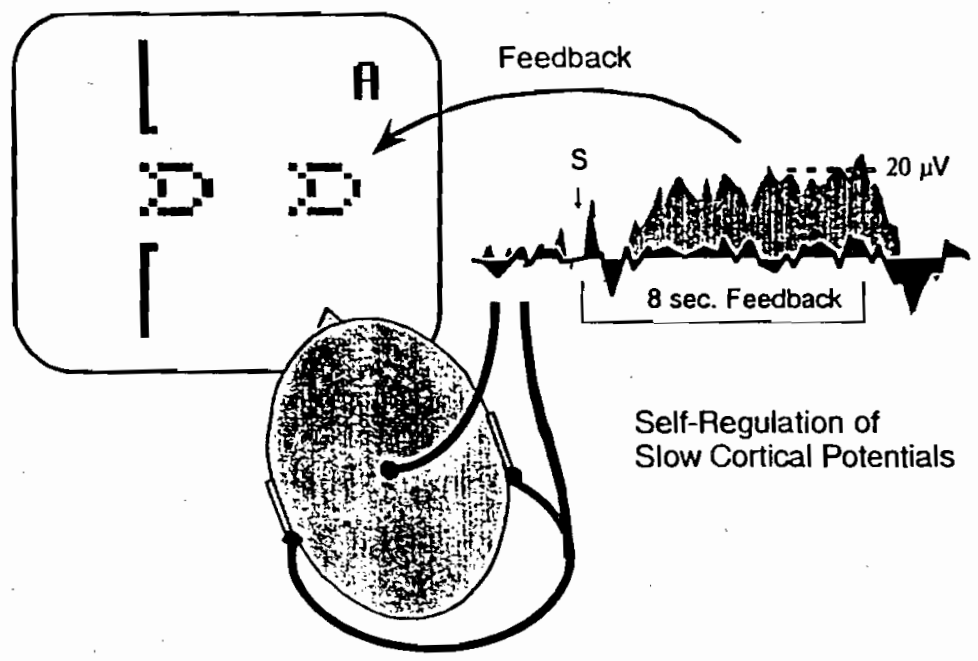

Visual feedback of slow EEG-changes:

Figure 5. Biofeedback device for instrumental learning of slow brain potentials. Screen with feedback stimulus ("rocket") and indication for cortical negativity ("A") or positivity ("B"). More negativity or positivity moves rocket forward (see text for explanation).

points appearing after each trial on the screen. Points are later exchanged for money. Usually there are 40-60 feedback trials, with a pseudorandom succession of A (i.e., positivity), or B (i.e., negativity). Trials of 'A' or 'B' are presented in transfer trials, asking the Ss to produce negativity or positivity without feedback. Different kinds of tasks are presented during transfer trials to test the effects of training on behavior and cognition. Ss are not informed as to whether A or B represent positive or negative SCP shifts. Data published during the past 15 years are highly consistent. (These and other data ruled out the possibility that unspecific activation or inhibition of the whole cortex is responsible for the effects achieved.)

a. Ss are able to discriminately produce local frontal, central, parietal, right-left hemispheric positive and negative SP (see Fig. 6 for an example from Birbaumer et al., 1992;

b. Behavioral and cognitive performance becomes highly predictable if the cortical locus and polarity (positive or negative) of the achieved DC changes are known: for example, left precentral negativity augments tactile performance and response speed of the right hand and vice versa. Positivity attenuates performance. 


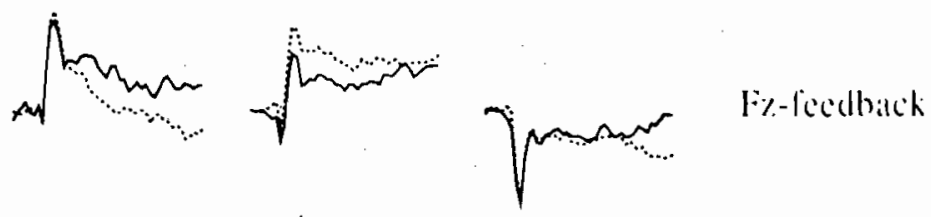

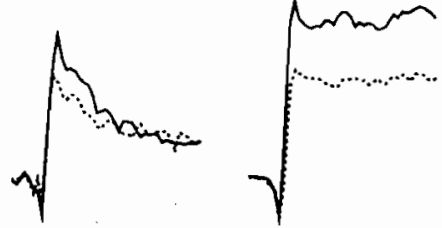<smiles>CCCCCC1CCCCC1C</smiles>

C\%-locdback

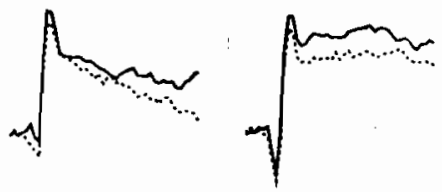

$\mathrm{F} \%$

Ferdback

$\mathrm{C} \%$

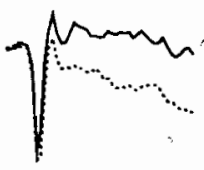

$\mathrm{P} \%$
Pr-lecdback increase neg. suppress neg.

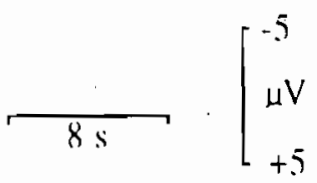

Figure 6. Slow potential response on negativity and positivity trials in third session of area-specific training (last feedback-only session). Slow potentials recorded from $\mathrm{Fz}, \mathrm{Cz}$, and $\mathrm{Pz}$ electrodes (abscissa) shown for groups receiving feedback at different mid-sagittal sites (ordinate). Reprinted with permission of Elsevier Science Publishers Ireland, Ltd., from Birbaumer $\mathrm{N}$ et al. (1992).

The general relationship between achieved amplitude of central SCP and attentional performance, for example, in a signal detection task (Lutzenberger et al., 1979) follows an invertedly u-shaped function. With more positivity "misses" become more frequent; with extreme negativities, more "false alarms" occur. Different tasks and locations were used, all pointing in the same direction: response speed, vigilance tasks, tactile tasks, motor reflexes (memory tasks led to less clear results) are primed by local negativities and inhibited by local positivities.

Several clinical groups with supposed disorders of threshold regulation and attention were investigated: frontal lobe lesions (Lutzenberger et al., 
1980b), psychoses-prone Ss (Elbert et al., 1983), schizophrenics (Schneider et al., 1992), children with attentional problems (Rockstroh et al., 1991), chronic pain patients (Haag et al., 1982), and, recently, drug-resistant epilepsies (Elbert et al., 1991) and patients with psychosomatic disorders (Lutzenberger et al., 1980b).

Patients with functional or neurological disorders of the prefrontal lobe such as schizophrenics, Ss with a high risk for schizophrenia, children with attention deficit disorders, and patients with bilateral lesions of the frontal lobes are unable to transfer the learned response and need extended training of as many as 30 sessions to learn SCP regulation. Patients with an increased awareness of internal and visceral bodily processes [such as pain patients or sufferers from migraine (Lutzenberger et al., 1980a) and depressed patients (Schneider et al., 1992)] show performance superior to that of normals.

A double-blind study (Rockstroh et al., 1993) on 24 drug-resistant adult epileptic patients proved the clinical utility of our paradigm and demonstrated, once again, that positivity hightens and negativity lowers excitation threshold. In the epilepsy study, patients had to discriminate central negativities and positivities during the first 20 training sessions. They were then trained to produce cortical positivity only to suppress seizure activity during the last 8 booster sessions.

Figure 7 shows the slow learning curve of the patients in producing

SP-differentiation for the first feedback-block

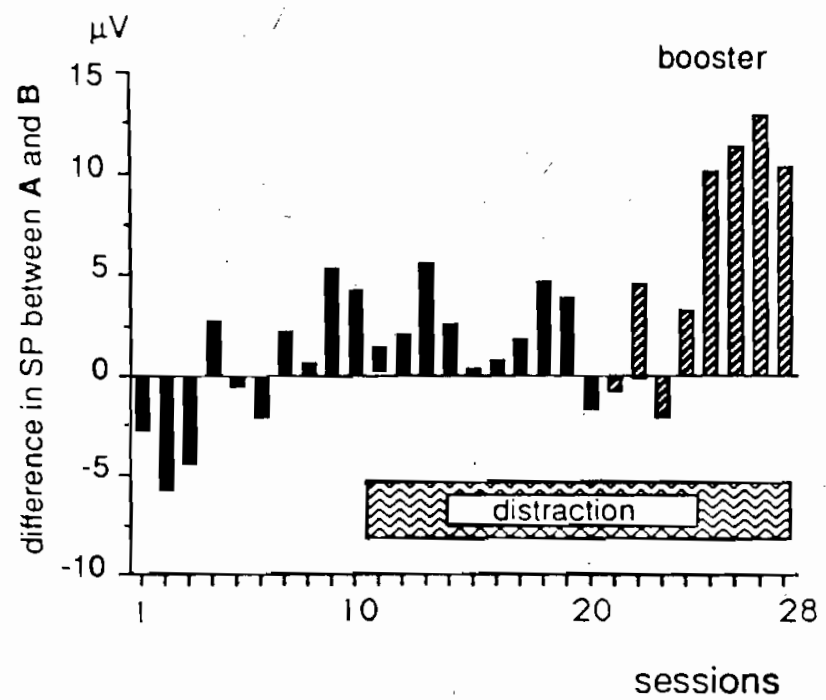

Figure 7. SP differentiation for the second transfer block (averages across 20 patients). 


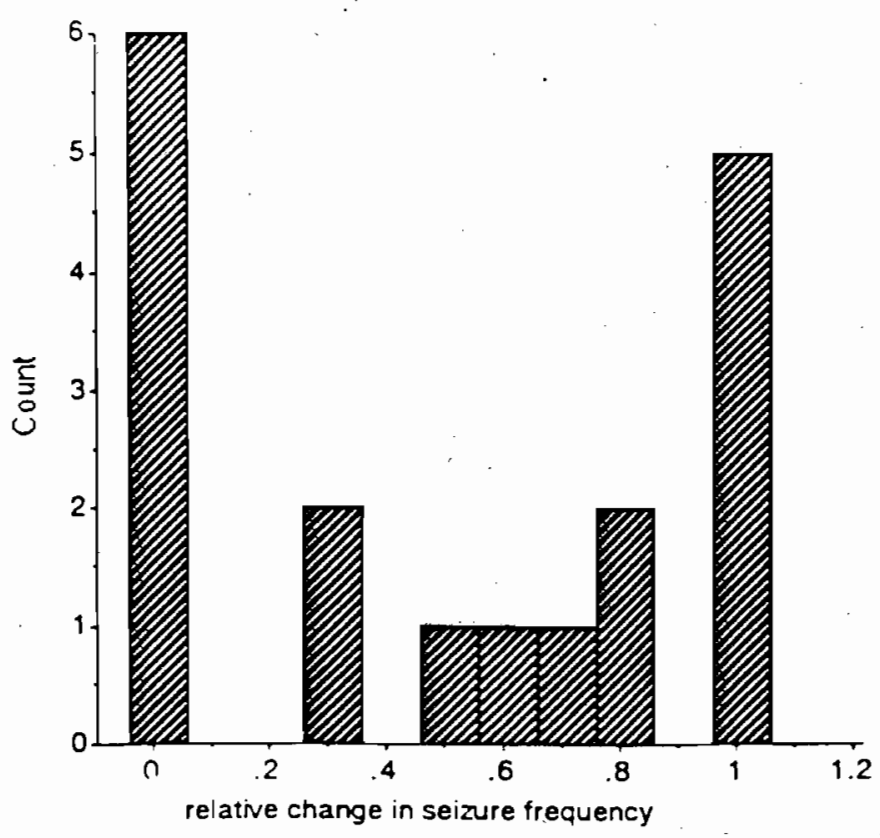

Figure 8. Frequency distribution of relative changes in seizure frequency, computed as fraction of median seizure incidence during follow-up divided by median during 3-month baseline. Value of 0 on abscissa means that patient has become seizure free during follow-up period; value of 1 , seizure incidence has remained unchanged. (From Rockstroh et al. 1993. With kind permission of Elsevier Science Publishers Ireland, Ltd.)

negativity and positivity "on command." The control group had the same conditions but received feedback of its alpha activity. None of the subjects in the control group improved. Figure 8 demonstrates the clinical outcome for the experimental group. With the exception of one patient, only patients who learned to produce negativities and positivities improved or became seizure free. We consider this an impressive confirmation of our hypotheses for "real" clinical life.

\section{Conclusion}

Let us conclude by emphasizing that spontaneous waxing and waning of cortical thresholds, in situations of free-floating attention and thought, is represented in spontaneous EEG tracings. These cortical transitions may only become visible if we look at them with a nonlinear, deterministic chaos viewpoint. On the other hand, goal-directed and therefore highly determinis- 
tic primed or prepared responses and thought do need local slow brain potentials to occur.

Despite its obvious clinical utility and experimental support, the presented hypothesis retains many doubts and uncertainties. We have not, however, intended to lead the reader into the misery of clarity (E. M. Cioran) or to a special destination. We do not need a special destination; we only wish to have incited your doubts. Let us conclude with a little poetry by the great Italian poet Giorgio Caproni, which characterizes all our scientific efforts more distinctively than we could:

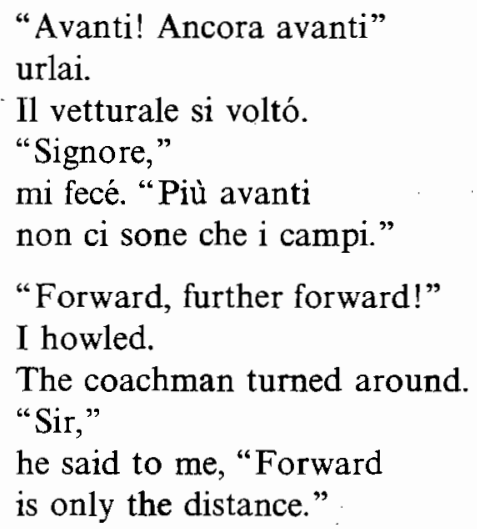

Acknowledgment. Research was supported by the Deutsche Forschungsgemeinschaft (DFG).

\section{References}

Basar E, Basar-Eroglu RJ, Schult J (1989): Chaos and alpha-preparation in brain function. In: Models of Brain Function, Corterill RMJ, ed., pp. 365-395. Cambridge: Cambridge University Press.

Bear MF, Cooper LN, Ebner FF (1987): A physiological basis of a theory of synapse modification. Science 237: 42-48.

Birbaumer N, Elbert T (1988): P3: By-product of a by-product? Behav Brain Sci $11: 375-376$.

Birbaumer N, Elbert R, Canavan A, Rockstroh B (1990): Slow potentials of the cerebral cortex and behaviour. Physiol Rev 70:1-41.

Birbaumer N, Roberts LE, Lutzenberger W, Rockstroh B, Elbert R: (1992) Areaspecific self-regulation of slow cortical potentials on the sagittal midline and its effects on behavior. Electroencephalogr Clin Neurophysiol 84, 353-361.

Birbaumer N, Elbert T, Rockstroh B, Daum I, Wolf P, Canavan A: Clinicalpsychological treatment of epileptic seizures: A controlled study. In: Perspectives and Promises of Clinical Psychology, Ehlers, A. et al., eds. New York: Plenum.

Braitenberg V (1978): Cell assemblies in the cerebral cortex. In: Theoretical Approach to Complex Systems, Heim R, Palm G, eds., pp. 171-188. Berlin: Springer-Verlag. 
Braitenberg V (1984): Vehicles-Experiments in Synthetic Psychology. Cambridge: MIT Press.

Braitenberg V, Shüz A (1991): Anatomy of the Cortex. A Statistical Approach to Its Structure. Berlin: Springer-Verlag.

Donchin E, Coles MGH (1988): P300 and context updating-. Reply to Verleger. Behav Brain Sci 11:357-374.

Elbert T (1987): Regulation kortikaler Erregbarkit: Irn EEG ein deterministisches Chaos? In: Zugang zum Verständnis höherer Hirnfunktionen durch das EEG, Weinmann H, ed., pp. 93-107. München: Zuckerschwerdt-Verlag.

Elbert T, Rockstroh B (1987): Threshold regulation-a key to the understanding of the combined dynamics of EEG and event-related potentials. $J$ Psychophysiol $4: 317-333$.

Elbert T, Rockstroh B (1990): Psychopharmakologie. Ein einführendes Lehrbuch. Heidelberg: Springer-Verlag.

Elbert T, Lutzenberger W, Rockstroh B, Birbaumer N (1983): When regulation of slow brain potentials fails-A contribution to the psychophysiology of perceptual aberration and anhedonia. In: Advances in Biological Psychiatry, Vol. 13, Mendlewicz J, van Praag HM, eds., Basel: Karger, pp. 98-106.

Elbert T, Rockstroh B, Lutzenberger W, Birbaumer N. (1980): Biofeedback of slow cortical potentials. J Electroencephalogr Clin Neurophysiol 48:293-301.

Elbert T, Rockstroh B, Lutzenberger W, Birbaumer N (1982): Slow brain potentials after withdrawal of control. Arch Psychiatr Nervenkr 232:201-214.

Elbert T, Rockstroh B, Birbaumer N, Canavan A, Lutzenberger W, van Bülow I (1991): Self-regulation of slow cortical potentials and its role in epileptogenesis. In: International Perspectives on Self-Regulation And Health, Carson JG; Seifert R, eds., pp. 65-94. New York: Plenum.

Freeman W (1991): The physiology of perception. Sci Am 264:78-85.

Gustafson B, Wigstrøm H, Abraham WC, Huang YY (1987): Long term potentiation in the hippocampus using depolarizing current pulses as the conditioning stimulus to single volley synaptic potentials. $J$ Neurosci 7(3):774-780.

Haag G, Gerber WD, Birbaumer N, Mayer K, Lutzenberger W, Schroth G (1982): Differentielle Indikation zur Psychotherapie der Migräne [Differential indication for behavior therapy of migraine]. In: Migräne Fortschritte der Klinischen Psychologie, Huber H, ed., pp. 205-232. München: Urban \& Schwarzenberg.

Hebb DO (1949): The Organization of Behavior. New York: Wiley.

Hebb DO (1961): Distinctive features of learning in the higher animal. In: Brain Mechanisms and Learning, Delafresnaye JF, ed. New York: Oxford University Press.

Kutas M, Hillyard SA (1980): Reading senseless sentences: Brain potentials reflect semantic incongruity. Science 207:203-204.

Lorente de No R (1943): Cerebral cortex: Architecture, intracortical connections, motor projections. In: Physiology of the Nervous System, Fulton FJ, ed. New York, Oxford University Press.

Lutzenberger W, Elbert T, Ray WJ, Birbaumer N (1992) The scalp distribution of the fractal dimension of the EEG and its variation with mental tasks Brain Topography 5, 27-34.

Lutzenberger W, Elbert T, Rockstroh B, Birbaumer N (1979): The effects of selfregulation of slow cortical potentials in a signal detection task. Int $J$ Neurosci 9:175-183. 
Lutzenberger W, Haag G, Birbaumer N, Stegagno L (1980a): Biofeedback langsamer kortikaler Potentiale (LKP): Zusammenhang von LKP und Reaktionslatenz bei Patienten mit psychosomatischen Störungen. Med Psychol 6:140-151.

Lutzenberger W, Birbaumer N, Elbert T, Rockstroh B, Bippus W, Breidt R (1980b): Self-regulation of slow cortical potentials in normal subjects and patients with frontal lobe lesions. In: Motivation, Motor and Sensory Processes of the Brain, Progress in Brain Research, Vol. 54, Kornhuber HH, Deecke L, eds., pp. 427-430. Amsterdam: Elsevier.

Mayer-Kress G, Yates FE, Benton L, Keidel M, Tirsch W, Pöppl SJ, Geist K (1988): Dimensional analysis of nonlinear oscillations in brain, heart, and muscle. Math Biosci 90:155-182.

McCallum WC (1988): Potentials related to expectancy, preparation and motor activity. In: Human Event-Related Potentials, EEG Handbook (revised series, Vol. 3), Picton TW ed., pp. 427-534. Amsterdam: Elsevier.

Mitzdorf U (1985): Current source-density method and application in cat cerebral cortex: Investigation of evoked potentials and EEG phenomena. Physiol Rev 65:37-99.

Palm G (1982): Neural Assemblies: An Alternative Approach to Artificial Intelligence. Berlin: Springer-Verlag.

Rockstroh B (1990): Hyperventilation-induced EEG-changes in hurnans and their modulation by an anti-convulsant drug. Epilepsy Res 7:146-154.

Rockstroh B, Elbert T, Lutzenberger W, Birbaumer N (1979): Slow cortical potentials under conditions of uncontrollability. Psychophysiology 16:374-380.

Rockstroh B, Müller M, Elbert T, Cohen R (1991): P300 and cortical dysfacilitation. In: The First European Psychophysiology Conference, Boelhouwer AJW, Brunia CHM, eds. Tilburg: Tilburg University Press.

Rockstroh B. Elbert T, Canavan A, Lutzenberger W, Birbaumer N (1989): Slow Brain Potentials and Behaviour, 2d Ed. München: Urban \& Schwarzenberg.

Rockstroh B, Dworkin BR, Lutzenberger W, Ernst M, Elbert T, Birbaumer N (1988): The influence of baroreceptor activation on pain perception. In: Behavioral Medicine in Cardiovascular Disorders, Elbert T, Langosch W, Steptoe A, Vaitl D, eds. Chichester: Wiley.

Rockstroh B, Elbert T, Lutzenberger W, Altenmüller E, Birbaumer N, Diener H-C, Dichgans J (1987): Effects of the anticonvulsant Carbamazepine on event-related brain potentials in humans. In: Evoked Potentials III, Barber R, Blum T, eds., pp. 361-369. Boston: Butterworths.

Rockstroh B, Elbert T, Birbaumer N, Düchting-Röth A, Wolf P, Daum I, Lutzenberger W, Dichgans J: 1993. Cortical self-regulation in patients with epilepsies Epilepsy Research 14, 63-72.

Rohracher H (1976): Einführung in die Psychologie. 12. Auf. München: Urban \& Schwarzenberg.

Schneider F, Rockstroh B, Heimann H, Lutzenberger W, Mattes R, Elbert T, Birbaumer N, Bartels M (1992). Self-regulation of slow cortical potentials in psychiatric patients: Schizophrenia. Biofeedback and Self-Regul 17, 277-291.

Schüz A, Palm G (1989): Density of neurons and synapses in the cerebral cortex of the mouse. $J$ Comp Neurol 286:442-455.

Skarda A, Freeman W (1987): How brains make chaos in order to make sense of the world. Behav Brain Sci 10:161-195.

von Bülow I, Elbert T, Rockstroh B, Lutzenberger W, Canavan A (1989): Effects of hyperventilation on EEG frequency and slow cortical potentials in relation to an anticonvulsant and epilepsy. $J$ Psychophysiol 3:147-154. 